Armin Schubert MD, ${ }^{*}$ Michael G. Licina MD,* Gary M. Glaze Do, $\dagger$ Lata Paranandi MsHP

\title{
Systemic lidocaine and human somatosensory- evoked potentials during sufentanil-isoflurane anaesthesia
}

The effect of systemically administered lidocaine on somatosensory evoked potentials (SSEPs) during general anaesthesia has not been widely reported. Knowledge of the influence of anaesthetic agents on evoked potentials assists in interpreting evoked potential waveforms. Accordingly, we studied the behaviour of cortical and subcortical (recorded at the second cervical vertebra) SSEPs after administration of intravenous lidocaine $\left(3 \mathrm{mg} \cdot \mathrm{kg}^{-1}\right.$ bolus followed by infusion at 4 $\left.\mathrm{mg} \cdot \mathrm{kg}^{-1} \cdot \mathrm{hr}^{-1}\right)$ during a sufentanil-based anaesthetic regimen in 16 patients undergoing abdominal or orthopaedic surgery. When compared to awake baseline recordings, the sufentanil-nitrous oxide, low-dose isoflurane anaesthetic depressed $N$, amplitude by approximately $40 \%$ and prolonged latency by $10 \%$. Fifteen minutes after establishment of this anaesthetic, the amplitude and latency of $N_{l}$ were $1.13 \pm 0.56 \mu \mathrm{V}$ and $19.81 \pm 1.63 \mathrm{msec}$, respectively. Within five minutes of adding lidocaine, amplitude decreased further to $0.84 \pm 0.39 \mu V(P=0.001)$, while latency was extended to $20.44 \pm 1.48 \mathrm{msec}(P=0.01)$. Lidocaine did not affect cervical amplitude and prolonged latency only minimally. Despite the observed effects on amplitude and latency, SSEP waveforms were preserved and interpretable. Plasma lidocaine levels obtained at 5,20 , and 40 minutes after lidocaine were 5.17 $\pm 1.33,3.76 \pm 1.14$, and $3.66 \pm 0.9 \mu \mathrm{g} \cdot d t^{-1}$, respectively. Our

\section{Key words}

ANAESTHETICS, INTRAVENOUS: sufentanil;

ANAESTHETICS, LOCAL: lidocaine;

MEASUREMENT TECHNIQUES: electroencephalography; MONITORING: evoked potentials.

From the Division of Anesthesiology* and Department of Biostatistics, The Cleveland Clinic Foundation, 9500 Euclid Avenue, Cleveland, Ohio 44195-5154 USA and the Department of Anesthesiology, Mercy General Hospital, $\uparrow$ Sacramento, CA 95819 USA.

Address correspondence to: Dr. Armin Schubert, Division of Anesthesiology, The Cleveland Clinic Foundation, 9500 Euclid Avenue, Cleveland, Ohio 44195-5154 USA.

Accepted for publication 29th March, 1992. results indicate that systemically administered lidocaine at therapeutic plasma levels acts synergistically with a sufentanilbased anaesthetic to depress the amplitude and prolong the latency of SSEPS.

Il existe peu de publications sur l'effet de la lidocaïne administrée par voie systémique sur les potentiels évoqués somatosensitifs (SSEP) pendant l'anesthésie générale. La connaissance des effets des agents anesthésiques sur les potentiels évoqués aide à l'interprétation des ondes de potentiels évoqués. Nous avons étudié l'effet de l'administration de lidocaïne par voie intraveineuse (bolus de $3 \mathrm{mg} \cdot \mathrm{kg}^{-1}$ suivi d'une perfusion de 4 $m g \cdot \mathrm{kg}^{-1} \cdot \mathrm{h}^{-1}$ ) surles SSEP corticaux et sous-corticaux (enregistré au niveau de la deuxième vertèbre cervical) chez 16 patients anesthésiés avec une technique à base de sufentanil pendant une chirurgie abdominale ou orthopédique. Comparativement aux enregistrements de base en état d'éveil, l'anesthésie à l'aide de sufentanil-protoxyde d'azote et faible dose d'isoflurane déprimait l'amplitude NI d'environ $40 \%$ et prolongeait la latence de 10\%. Après 15 minutes d'anesthésie, l'amplitude et la latence de $N 1$ étaient de $1,13 \pm 0,56 \mu \mathrm{V}$ et $19,81 \pm 1,63 \mathrm{msec}$ respectivement. Cinq minutes après l'addition de lidocaïne, l'amplitude a diminué à $0,84 \pm 0,39 \mu \mathrm{V}(P<0,001)$ tandis que la latence a augmenté à 20,44 $\pm 1,48 \mathrm{msec}(P<0,01)$. La lidocaïne n'a pas affecté l'amplitude cervical et a très peu prolongé la latence. Malgré les effets observés surl'amplitude et la latence, les ondes SSEP étaient préservées et interprétables. Les niveaux plasmatiques de lidocaïne à 5,20 et 40 minutes après l'injection étaient de $5,17 \pm 1,33,3,76 \pm 1,14$ et 3,66 $\pm 0,9 \mu \mathrm{g} \cdot d t^{1}$ respectivement. Nos résultats démontrent que la lidocaïne administrée par voie systémique à des niveaux plasmatiques thérapeutiques agit en synergie avec une technique anesthésique à base de sufentanil en provoquant une dépression de l'amplitude et une prolongation de la latence des SSEP.

Somatosensory evoked potentials (SSEPs) are frequently used to indicate central nervous system integrity during certain neurosurgical and orthopaedic procedures. However, anaesthetics affect SSEP amplitude and latency, 
particularly in cortical recordings. ${ }^{1-3}$ Knowing the effect of anaesthetics and other therapeutic agents that may be administered perioperatively helps with the interpretation of evoked potential waveforms and in the management of anaesthesia for patients who require such electrophysiologic monitoring.

Lidocaine is administered intravenously either as a component of the anaesthetic or in the management of intraoperative dysrhythmias. However, the influence of systemic lidocaine on SSEPs during general anaesthesia has not been widely reported. This is of interest to the anaesthetist who cares for patients requiring SSEP monitoring during procedures that are associated with the risk of injury to spinal or brain function. We therefore investigated the effect of intravenously administered lidocaine on median nerve SSEPs during a background anaesthetic technique commonly used for neurosurgical patients.

\section{Methods}

With institutional approval and written informed consent, we studied 16 patients (ages 22 to $46 \mathrm{yr}$ ) undergoing elective abdominal or orthopaedic surgery. All patients received premedication with triazolam $(0.25$ to $0.50 \mathrm{mg}$ po) and morphine $\left(0.1\right.$ to $\left.0.15 \mathrm{mg} \cdot \mathrm{kg}^{-1} \mathrm{im}\right) 60$ to $90 \mathrm{~min}$ before induction. Anaesthesia was induced with thiopentone ( 4 to $\left.5 \mathrm{mg} \cdot \mathrm{kg}^{-1}\right)$ and sufentanil $\left(0.5\right.$ to $\left.1.0 \mu \mathrm{g} \cdot \mathrm{kg}^{-1}\right)$ and maintained with sufentanil (by continuous infusion at a rate of 0.25 to $0.5 \mu \mathrm{g} \cdot \mathrm{kg}^{-1} \cdot \mathrm{hr}^{-1}$ ), nitrous oxide (50\% inspired) and isoflurane ( $0.5 \%$ inspired). Muscle relaxation was provided by non-depolarizing relaxants. After a postinduction equilibration period of 15 minutes, lidocaine ( $3 \mathrm{mg} \cdot \mathrm{kg}^{-1}$ ) was infused over two minutes, followed by a constant infusion at $4 \mathrm{mg} \cdot \mathrm{kg}^{-1} \cdot \mathrm{hr}^{-1}$.

Using a Cadwell 5200A (Cadwell Laboratories, Inc., Kennewick, WA, USA) electrophysiological monitoring system, SSEPs were recorded immediately before induction, at six and one minutes before lidocaine administration, and at five- and ten-minute intervals thereafter. Stimuli consisting of $150 \mu \mathrm{sec}$ constant current pulses were applied to the skin overlying the median nerve at the wrist. Stimulus intensity was adjusted to motor threshold plus $50 \%$. Signals were recorded simultaneously from surface gold-cup electrodes (affixed with collodion) at the level of the second cervical vertebra and the area of the scalp overlying the contralateral cortex $\left(\mathrm{C}^{\prime}\right.$ or $\mathrm{C}^{\prime}$, International 10-20 System). The electrical signals were recorded over a time base of $50 \mathrm{msec}$, with band pass filters of 30 and $500 \mathrm{~Hz}$. The Cadwell preamplifier setting was $10 \mu \mathrm{V}$ per division. Electrode impedance was adjusted to less than $3 \mathrm{kOhms}$. Three hundred signals were averaged into one evoked potential waveform. For each channel, an 8-bit analogue-to-digital converter digitized

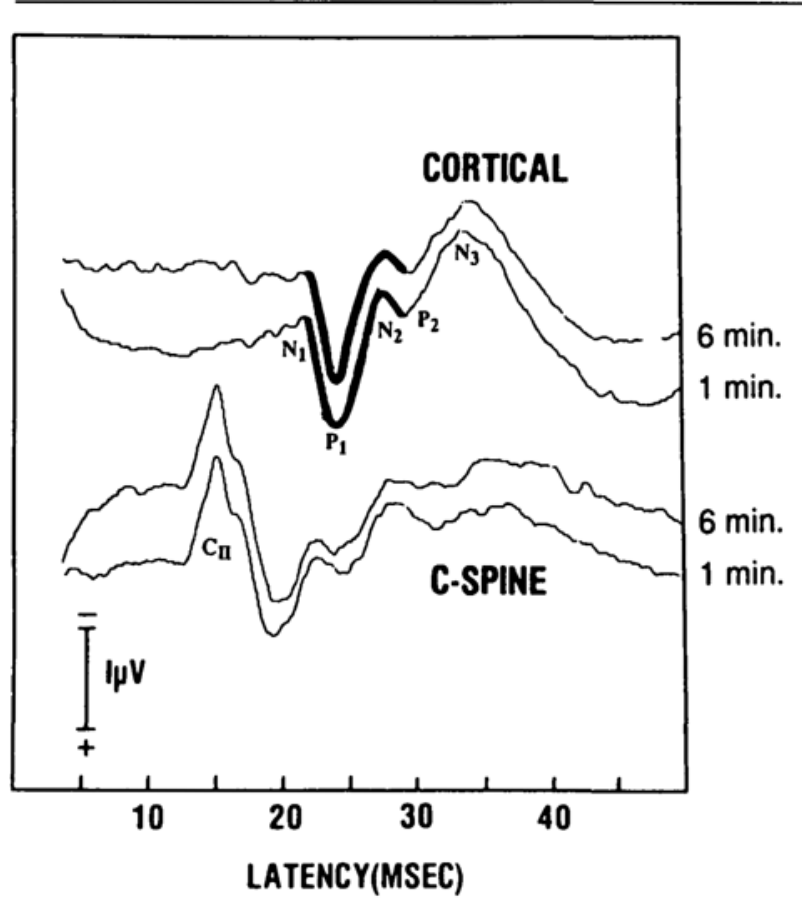

FIGURE la Example of scalp ("cortical")and cervically ("C-spine") recorded SSEP waveforms obtained during the sufentanil-isoflurane anaesthetic, one and six minutes prior to the systemic administration of lidocaine.

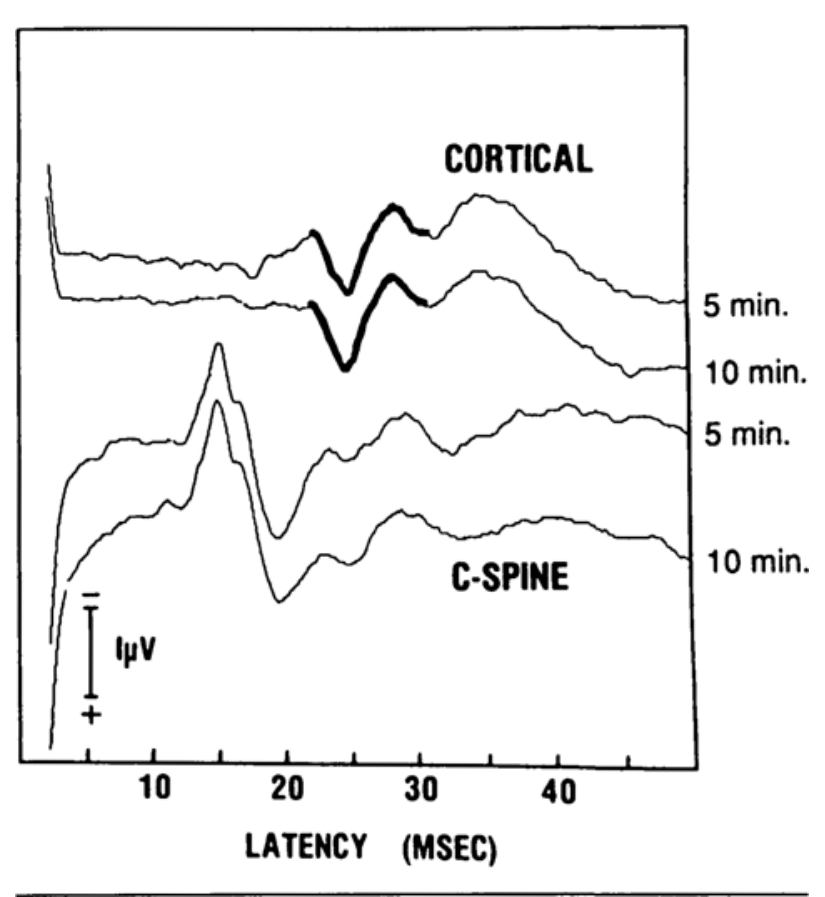

FIGURE 1b SSEP waveforms five and ten minutes after lidocaine 3 $\mathrm{mg} \cdot \mathrm{kg}^{-1}$ iv. Note the contraction in $N_{1}$ waveform amplitude with relative sparing of cervical amplitude. 
TABLE I Cardiorespiratory data and anaesthetic levels

\begin{tabular}{lcccccc}
\hline & Pre-lido & $5 \min$ & $10 \min$ & $20 \min$ & $30 \min$ & $40 \min$ \\
\hline MAP $(\mathrm{mmHg})$ & $73 \pm 12$ & $76 \pm 9$ & $75 \pm 10$ & $71 \pm 11$ & $79 \pm 13$ & $79 \pm 16$ \\
$\mathrm{HR}\left(\right.$ beats $\left.\cdot \mathrm{min}^{-1}\right)$ & $66 \pm 11$ & $66 \pm 11$ & $65 \pm 12$ & $64 \pm 11$ & $62 \pm 10$ & $66 \pm 9$ \\
$\mathrm{~T}\left({ }^{\circ} \mathrm{C}\right)$ & $35.9 \pm 0.2$ & $35.8 \pm 0.3$ & $35.8 \pm 0.3$ & $35.7 \pm 0.4$ & $35.7 \pm 0.3$ & $35.6 \pm 0.3$ \\
PETCO $(\mathrm{mmHg})$ & $30.1 \pm 2.6$ & $29.9 \pm 3.0$ & $30.8 \pm 2.4$ & $30.7 \pm 2.4$ & $30.9 \pm 2.4$ & $31.0 \pm 3.0$ \\
FET $_{\text {ISO }}(\%)$ & $0.32 \pm 0.03$ & $0.34 \pm 0.03$ & $0.34 \pm 0.03$ & $0.34 \pm 0.03$ & $0.35 \pm 0.03$ & $0.34 \pm 0.03$ \\
Plasma lidocaine $\left(\mu \mathrm{g} \cdot \mathrm{dl}^{-1}\right)$ & - & $5.17 \pm 1.33$ & - & $3.76 \pm 1.14$ & - & $3.66 \pm 0.46$ \\
\hline
\end{tabular}

waveforms at $18 \mathrm{kHz}$. All evoked potential waveforms were stored on magnetic disc for later analysis. The pertinent waveform generated from the cervical recording electrode consisted of a negativity at approximately 14 msec $\left(\mathrm{C}_{\mathrm{II}} \mathrm{s}\right)$. In tracings recorded from the cortical electrode, negativities at approximately 20,24 , and $33 \mathrm{msec}$ $\left(\mathrm{N}_{1}, \mathrm{~N}_{2}\right.$, and $\left.\mathrm{N}_{3}\right)$ followed by positive deflections at approximately 22 and $27 \mathrm{msec}\left(\mathrm{P}_{1}\right.$ and $\left.\mathrm{P}_{2}\right)$ were analyzed (Figures 1a, 1b). Peak-to-trough amplitude values and central conduction time (CCT), that is, the $\mathrm{C}_{\mathrm{II}} \mathrm{s}-\mathrm{N}_{1}$ interlatency difference, were also measured.

With each SSEP measurement, mean arterial blood pressure (MAP), heart rate (HR), oesophageal temperature (T), end-tidal $\mathrm{CO}_{2}\left(\mathrm{PETCO}_{2}\right)$, and end-tidal isoflurane $\left(\mathrm{FET}_{1 S O}\right)$ were also recorded. Venous plasma lidocaine levels were obtained 5,20 , and $40 \mathrm{~min}$ after lidocaine was begun. The infusion was maintained for at least $40 \mathrm{~min}$; however, some anaesthetists elected to continue intravenous lidocaine anaesthesia throughout the case. Lidocaine levels were measured by fluorescence polarization immunoassay. Heated humidification and warming blankets were used to maintain body temperature. Cooling of the stimulated extremity was avoided by using the opposite arm for intravenous fluid administration. Mechanical ventilation was adjusted to maintain a stable level of $\mathrm{PETCO}_{2}$.

Statistical analyses included the paired $t$ test or Wilcoxon signed rank test, where appropriate, to evaluate the stability of the pre-lidocaine postinduction measurements and to detect differences over time when compared with the pre-lidocaine baseline data. Pre-lidocaine baseline data were compared with five follow-up times in pairwise fashion. Paired $t$ tests were used instead of repeated measures analysis of variance, because of occasional missing data points. Since the latter were distributed over four patients at different observation points, the use of ANOVA would have resulted in deletion of a disaproportionate amount of data. To help account for multiple comparisons, the Bonferroni method of adjustment $(0.05 / \#$ pairwise comparisons) was used to arrive at a stricter criterion for statistical significance $(P=0.01)$.
TABLE II Baseline SSEP data prior to induction (A) and prior to administration of lidocaine $(B, C)$

\begin{tabular}{lccr}
\hline Amplitude $(\mu V)$ & $A$ & \multicolumn{1}{l}{$B$} & \multicolumn{1}{l}{$C^{*}$} \\
\hline $\mathrm{C}_{\mathrm{II}} \mathrm{s}$ & $3.25 \pm 1.06$ & $2.95 \pm 1.12$ & $3.0 \pm 1.04$ \\
$\mathrm{~N}_{1}-\mathrm{P}_{1}$ & $2.0 \pm 0.67 \dagger$ & $1.16 \pm 0.58$ & $1.09 \pm 0.55$ \\
$\mathrm{P}_{1}-\mathrm{N}_{2}$ & $1.16 \pm 0.69$ & $0.81 \pm 0.68$ & $0.78 \pm 0.61$ \\
$\mathrm{~N}_{2}-\mathrm{P}_{2}$ & $0.85 \pm 0.70$ & $0.64 \pm 0.48$ & $0.56 \pm 0.45$ \\
$\mathrm{P}_{2}-\mathrm{N}_{3}$ & $1.91 \pm 0.98$ & $1.41 \pm 0.74$ & $1.31 \pm 0.72$ \\
& & & \\
Latency (msec) & & & \\
$\mathrm{C}_{\mathrm{II}} \mathrm{S}$ & $13.16 \pm 1.07$ & $13.40 \pm 1.09$ & $13.40 \pm 1.12$ \\
$\mathrm{~N}_{1}$ & $18.85 \pm 1.01 \dagger$ & $19.76 \pm 1.57$ & $19.85 \pm 1.70$ \\
$\mathrm{P}_{1}$ & $21.45 \pm 1.14 \dagger$ & $22.07 \pm 1.39$ & $22.18 \pm 1.33$ \\
$\mathrm{~N}_{2}$ & $24.10 \pm 1.73$ & $24.27 \pm 1.39$ & $24.30 \pm 1.35$ \\
$\mathrm{P}_{2}$ & $26.23 \pm 2.12$ & $27.07 \pm 1.80$ & $27.15 \pm 2.07$ \\
$\mathrm{~N}_{3}$ & $30.91 \pm 2.16 \dagger$ & $33.50 \pm 2.21$ & $33.47 \pm 2.39$ \\
$\mathrm{CCT}\left(\mathrm{N}_{1}-\mathrm{C}_{\mathrm{ll}}\right)$ & $5.69 \pm 0.47 \dagger$ & $6.36 \pm 1.0$ & $6.45 \pm 1.17$ \\
\hline
\end{tabular}

$* P>0.05$ vs $\mathrm{B}$ (ns)

$+P<0.01$ vs average of $B$ and $C$.

$\mathrm{A}=$ pre-induction; $\mathrm{B}=$ post-induction, six min pre-lidocaine; $\mathrm{C}=$ postinduction, one min pre-lidocaine.

\section{Results}

Although HR and MAP decreased during induction of anaesthesia, no further changes were observed after the administration of lidocaine. Similarly, T, $\mathrm{PETCO}_{2}$ and $\mathrm{FET}_{\text {ISO }}$ were unchanged during the study period (see Table I).

Baseline SSEP results recorded before and after induction of anaesthesia are shown in Table II. The sufentanil-based background anaesthetic resulted in a reduction in $N_{1}-P_{1}$ amplitude of approximately $40 \%$ with a small $(<10 \%)$ increase in latency (see Table II). In no case was the $N_{1}$ waveform obliterated. However, in four patients, the later peaks $P_{1}, N_{2}$ and $P_{2}$ were not identifiable. Somatosensory evoked potential measurements obtained six and one minutes before administration of lidocaine did not differ. Therefore, they were averaged and used as a baseline value for post-lidocaine data.

Tables III and IV show the effect of lidocaine on SSEP latency and amplitude. The addition of lidocaine to the 
TABLE III Effect of lidocaine iv on SSEP latency

\begin{tabular}{|c|c|c|c|c|c|c|}
\hline & Pre-lidot & $5 \min$ & $10 \mathrm{~min}$ & $20 \min$ & $30 \mathrm{~min}$ & $40 \mathrm{~min}$ \\
\hline $\mathrm{C}_{\mathrm{II}} \mathrm{s}$ & $13.40 \pm 1.10$ & $13.50 \pm 1.17$ & $13.58 \pm 1.17$ & $13.59 \pm 1.22$ & $13.67 \pm 1.17^{*}$ & $13.72 \pm 1.18^{*}$ \\
\hline$N_{1}$ & $19.81 \pm 1.63$ & $20.44 \pm 1.48^{*}$ & $20.38 \pm 1.49 *$ & $20.35 \pm 1.56^{*}$ & $20.25 \pm 1.79$ & $20.37 \pm 1.60$ \\
\hline$P_{1}$ & $22.12 \pm 1.28$ & $23.0 \pm 1.65^{*}$ & $22.8 \pm 1.57 *$ & $22.89 \pm 1.54^{*}$ & $22.78 \pm 1.38^{*}$ & $22.88 \pm 1.59 *$ \\
\hline $\mathrm{N}_{2}$ & $24.28 \pm 1.37$ & $24.85 \pm 1.61^{*}$ & $24.91 \pm 1.51^{*}$ & $24.96 \pm 1.53^{*}$ & $25.11 \pm 1.51^{*}$ & $25.43 \pm 1.40^{*}$ \\
\hline$P_{2}$ & $27.11 \pm 1.96$ & $27.90 \pm 1.46^{*}$ & $27.86 \pm 1.32 *$ & $27.97 \pm 1.45^{*}$ & $28.02 \pm 1.58^{*}$ & $28.06 \pm 1.56^{*}$ \\
\hline $\mathrm{N}_{3}$ & $33.49 \pm 2.23$ & $34.66 \pm 2.25 *$ & $35.16 \pm 2.6^{*}$ & $35.45 \pm 2.82^{*}$ & $34.76 \pm 2.31^{*}$ & $35.36 \pm 2.77^{*}$ \\
\hline $\mathrm{CCT}$ & $6.41 \pm 1.07$ & $6.94 \pm 0.70^{*}$ & $6.8 \pm 0.68^{*}$ & $6.76 \pm 0.86$ & $6.58 \pm 1.12$ & $6.65 \pm 0.87$ \\
\hline
\end{tabular}

$\dagger$ Average of two pre-lidocaine data points.

$* P<0.01$ vs pre-lidocaine average.

TABLE IV Effect of lidocaine iv on SSEP amplitude

\begin{tabular}{lllllll}
\hline & Pre-lidot & $5 \min$ & $10 \min$ & $20 \min$ & $30 \min$ \\
\hline $\mathrm{C}_{11} \mathrm{~S}$ & $2.97 \pm 1.06$ & $3.11 \pm 1.04$ & $3.02 \pm 1.02$ & $2.88 \pm 0.94$ & $2.75 \pm 0.92$ \\
$\mathrm{~N}_{1}-\mathrm{P}_{1}$ & $1.13 \pm 0.56$ & $0.84 \pm 0.39^{*}$ & $0.79 \pm 0.45^{*}$ & $0.75 \pm 0.32^{*}$ & $0.90 \pm 0.30$ & $2.75 \pm 0.92$ \\
$\mathrm{P}_{1}-\mathrm{N}_{2}$ & $0.80 \pm 0.64$ & $0.51 \pm 0.36^{*}$ & $0.53 \pm 0.39$ & $0.49 \pm 0.31^{*}$ & $0.46 \pm 0.31^{*}$ \\
$\mathrm{~N}_{2}-\mathrm{P}_{2}$ & $0.60 \pm 0.47$ & $0.82 \pm 0.44$ & $0.67 \pm 0.34$ & $0.58 \pm 0.37$ & $0.46 \pm 0.32$ \\
$\mathrm{P}_{2}-\mathrm{N}_{3}$ & $1.36 \pm 0.73$ & $1.54 \pm 0.74$ & $1.28 \pm 0.65$ & $1.17 \pm 0.66$ & $1.15 \pm 0.63$ & $0.47 \pm 0.33$ \\
\hline
\end{tabular}

†Average of two pre-lidocaine data points.

${ }^{*} P<0.01$ vs pre-lidocaine average.

sufentanil-isoflurane anaesthetic resulted in a small but statistically significant prolongation of all latencies measured, as well as in a prolongation of CCT (Figure 2). Lidocaine also affected $N_{1}-P_{1}$ and $\left.P_{1}-P_{2}\right)$ amplitude, diminishing it significantly by $25-30 \%$ (Figure $3 \mathrm{a}$ ). The amplitude at later waveform peaks $\left(\mathrm{N}_{2}-\mathrm{P}_{2}, \mathrm{P}_{2}-\mathrm{N}_{3}\right)$ was largely unchanged although a trend towards a transient enhancement at five minutes was seen (Figure $3 b$ ). No waveform peaks were lost as a result of lidocaine. The SSEP effects of the lidocaine bolus plus infusion regimen were clearly evident five minutes after drug administration and persisted for at least 40 minutes.

\section{Discussion}

Our data indicate that intravenous lidocaine depresses cortical SSEP amplitude by $25 \%$ to $30 \%$ and prolongs latency by approximately $5 \%$ when administered during an anaesthetic regimen frequently used for patients requiring neurophysiological monitoring. The dosing regimen employed in the study resulted in plasma lidocaine concentrations considered therapeutic for arrhythmia control.

During anaesthesia, lidocaine may be administered systemically for a variety of reasons. In humans, lidocaine reduces MAC by approximately $30 \%$ at plasma concentrations comparable to those attained in the present study. ${ }^{4}$ It also has been reported to suppress the cough reflex and may blunt the haemodynamic and intracranial pressure responses to airway manipulation. ${ }^{5,6}$ The agent has therefore been administered by continuous infusion to augment

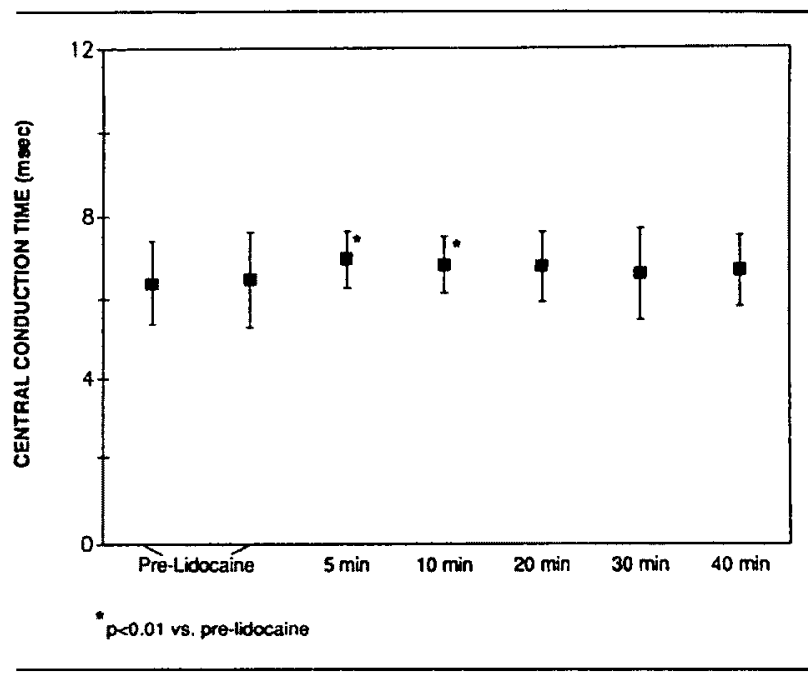

FIGURE 2 Despite achieving statistical significance, the prolongation of central conduction time after lidocaine was relatively minor $(<10 \%)$. Note the stability of the pre-lidocaine measurements.

depth of anaesthesia, and by bolus to guard against stimulation from airway manoeuvres. ${ }^{7-9}$ Lidocaine infusions have also been employed in the treatment of acute postoperative pain ${ }^{9,10}$ and chronic pain syndromes. ${ }^{11,12}$

The influence of systemically administered local anaesthetics on evoked potentials has been investigated primarily in the context of the auditory-evoked response. Both systemically administered lidocaine ${ }^{13}$ and its primary amine congener tocainide ${ }^{14}$ have been found to influence 


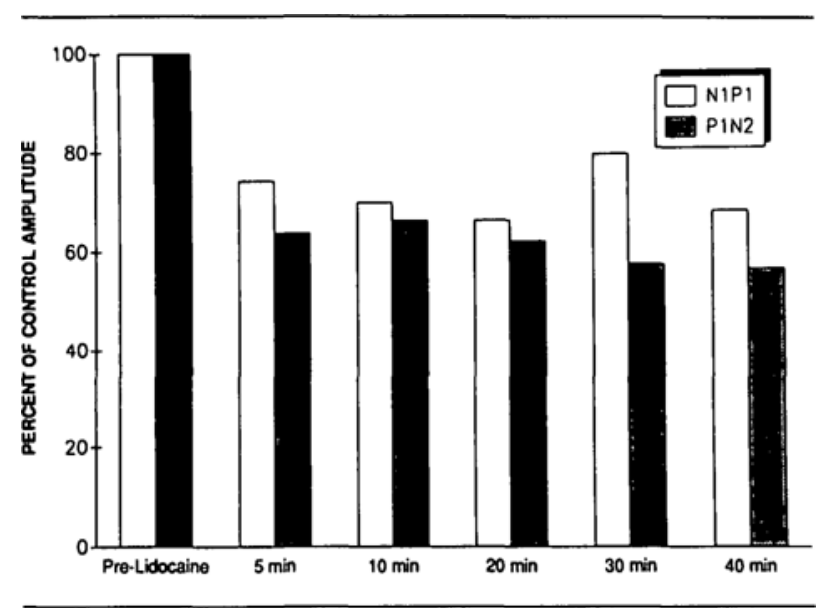

FIGURE 3a Amplitude effect of lidocaine: $N_{1}-P_{1}$ and $P_{1}-N_{2}$ amplitude is moderately depressed from pre-lidocaine, post-induction baseline.

the brainstem auditory response (BAER). At very low doses, the effect is minimal. ${ }^{15}$ At continuous infusion rates commonly employed during arrhythmia control, lidocaine affected the more central components of the human BAER (wave $V$ ) by increasing latency and reducing amplitude. At much higher doses $\left(20 \mathrm{mg} \cdot \mathrm{kg}^{-1}\right)$ all components of the cat BAER were prolonged, ${ }^{16}$ and in guinea pigs the BAER response disappeared entirely at $30 \mathrm{mg} \cdot \mathrm{kg}^{-1} \cdot 17$

Somatic-evoked sensory nerve activity at the spinal cord level is subject to the influence of systemically administered lidocaine and tocainide. In spinal rats, lidocaine at doses greater than $1 \mathrm{mg} \cdot \mathrm{kg}^{-1}$ substantially reduced the amplitude of evoked polysynaptic reflexes. ${ }^{18}$ Although also affecting A-beta-, A-delta- and C-fibre evoked activity, lidocaine and tocainide preferentially depressed C-fibre- evoked activity. ${ }^{18,19}$ Similarly, Dohi et al., ${ }^{20}$ found that intravenously administered lidocaine suppressed noxious-evoked activity in dorsal horn neurons of decerebrate cats. At the spinal level, systemic lidocaine may enhance monosynaptic reflexes, ${ }^{21}$ possibly through depression of local inhibitory neuronal influences. Cortical neurons, however, appear to be subject to a direct inhibitory action of the drug at doses encountered clinically. ${ }^{1,22,23}$

Depression of multisynaptic pathways at the spinal and supraspinal levels is therefore associated with the systemic administration of lidocaine. The results of the present investigation were consistent with this notion. The major depressant effect of lidocaine on SSEP latency in the present study occurred at the level of $\mathrm{N}_{1}$ and $\mathrm{N}_{2}$ waveforms, but the latency of the cervical potential $\left(\mathrm{C}_{11} \mathrm{~s}\right)$ was also prolonged to a lesser degree (Table III). The transient enhancement of later cortical waveform components $\left(P_{2}-N_{3}\right)$ is unexplained but may represent release of inhibitory activity.

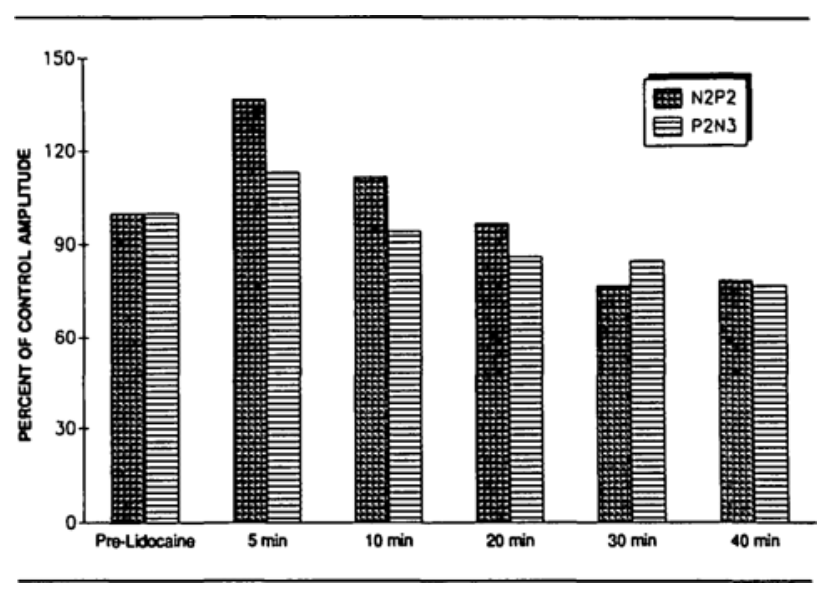

FIGURE $3 b$ The amplitude of later $\left(\mathrm{N}_{2}-\mathrm{P}_{2}, \mathrm{P}_{2}-\mathrm{N}_{3}\right)$ waveform components is variably affected by lidocaine.

The influence of systemic lidocaine on intraoperatively recorded SSEPs has only recently been recognized. ${ }^{24,25}$ In a study of intravenous lidocaine for cerebral protection during focal ischaemia, Gelb et al. ${ }^{26}$ reported that lidocaine $5 \mathrm{mg} \cdot \mathrm{kg}^{-1}$ resulted in a $40 \%$ reduction of feline cortical SSEP amplitude prior to middle cerebral artery occlusion. Mackie et al. ${ }^{27}$ reported a lack of changes in both the SSEP and BAER after lidocaine was administered systemically to four healthy awake human volunteers at a dose sufficient to achieve blood levels of 2 to $5 \mu \mathrm{g} \cdot \mathrm{dl}^{-1}$. Their small sample size may well have prevented the detection of a significant effect, as a trend toward prolonged SSEP latency was evident in the data. The unanaesthetized state of their subjects could also have contributed. It is conceivable that lidocaine acts synergistically with general anesthetics to depress SSEP waveforms.

Our data may be criticized because of the possibility that factors other than the administration of lidocaine could have accounted for the SSEP changes observed. However, we believe that this is unlikely for several reasons. First, such potential confounding variables as temperature, carbon dioxide tension, or inhaled anaesthetic concentration were rigidly controlled during the entire recording period. Second, the two pre-lidocaine baseline recordings were similar, suggesting that the 15 -min equilibration period had, indeed, resulted in a stable anaesthetic state. Furthermore, the changes observed were generally maximal at the five- or ten-minute recordings and progressed no further with time. This stability, together with the stable baseline recordings, argues against the observed changes having occurred merely as a result of the passage of time.

The present findings should be of interest to the anaesthetist and neurophysiologist involved in the care of patients who are to have SSEPs monitored intraoperatively. When an anaesthetic similar to the one in the 
present study is employed, the systemic administration of lidocaine may reduce cortical amplitude to a point where the cumulative change could give the appearance of neural injury. It would, therefore, be advisable to curtail the administration of $i v$ lidocaine during critical SSEP monitoring periods. Similarly, if baseline SSEP amplitude is already low, the addition of lidocaine to the anaesthetic regimen is not desirable because of the potential for further amplitude depression. If lidocaine is needed for arrhythmia control, it may be necessary to discontinue nitrous oxide to counteract its SSEP-depressant effect. Nitrous oxide reduces SSEP amplitude by up to $50 \% .^{28}$

Kasaba et al. ${ }^{24}$ observed prolongation of median nerve SSEPs after epidural lidocaine anaesthesia and postulated that this effect resulted from the central action of systemically absorbed local anaesthetic. These investigators later showed similar SSEP latency prologation with intravenously administered lidocaine at plasma lidocaine levels comparable to those achieved during epidural anaesthesia. ${ }^{25}$ Our findings support their conclusion that SSEP changes during epidural anaesthesia may in part be the result of systemic absorption. In light of these observations, previous data reporting the influence of epidural local anaesthesia on SSEPS should be re-evaluated, since the systemic effect of local anaesthetic may have accounted for some of the changes observed. Epidural administration of lidocaine can result in plasma levels closely approximating those observed in the present study. ${ }^{24}$ Depression of cortically ${ }^{19,30}$ and spinally ${ }^{30}$ recorded amplitude and prolongation of latency after administration of local anaesthetic thus may, in part, have been occasioned by systemically absorbed drug.

In summary, we observed a reduction in SSEP amplitude and a slightly prolonged latency when patients anaesthetized with a sufentanil-nitrous oxide-isoflurane regimen were given intravenous lidocaine to achieve mean plasma levels of 3.7 to $5.2 \mu \mathrm{g} \cdot \mathrm{dl}^{-1}$. This information can be of use in the intraoperative management of patients requiring SSEP monitoring when lidocaine is administered intravenously either as an adjunct to anaesthesia or as an antiarrhythmic agent.

\section{Acknowledgement}

The authors gratefully acknowledge the outstanding secretarial support of Mrs. Lorie Peterson.

\section{References}

1 Peterson DO, Drummond JC, Todd MM. Effects of halothane, enflurane, isoflurane and nitrous oxide on somatosensory evoked potentials in humans. Anesthesiology 1986; 65: 35-40.

2 Koht A, Schuetz W, Schmidt G, Schramm J, Watanabe E.
Effects of etomidate, midazolam and thiopental on median nerve somatosensory evoked potentials and the additive effects of fentanyl and nitrous oxide. Anesth Analg 1988; 67: 435-41.

3 Schubert A, Drummond JC, Peterson DO, Saidman LJ. The effect of high-dose fentanyl on human median nerve somatosensory-evoked responses. Can J Anaesth 1987; 34: 35-40.

4 Himes RS, DiFazio CA, Burney RG. Effects of lidocaine on the anesthetic requirement for nitrous oxide and halothane. Anesthesiology 1977; 47: 437-40.

5 Pulton TJ, James FM. Cough suppression by lidocaine. Anesthesiology 1979; 50: 470-2.

6 Harmill JF, Bedford RF, Weaver DC, Colohan AR. Lidocaine before endotracheal intubation: intravenous or laryngotracheal? Anesthesiology 1981; 55: 578-81.

7 Blancato LS, Peng AT, Alonsabe D. Intravenous lidocaine as an adjunct to general anesthesia for endoscopy. Anesth Analg 1969; 48: 224-7.

8 DeClive-Lowe SG, Desmond J, North J. Intravenous lignocaine anesthesia. Anesthesiology 1958, 13: 138-46.

9 Bartlett EE, Hutaserani. Xylocaine for the relief of postoperative pain. Anesth Analg 1961; 40: 296-304.

10 Cassuto J, Wallin G, Hogstrom S, Faxen A, Rimback G. Inhibition of postoperative pain by continuous low dose infusion of lidocaine. Anesth Analg 1985; 64: 971-4.

11 Boas RA, Covino BG, Shahnarian A. Analgesic response to iv lignocaine. Brit J Anaesth 1982; 54: 501-5.

12 Tanelian $D L$, Brose $W G$. Neuropathic pain can be relieved by drugs that are use-dependent sodium channel blockers: lidocaine, carbamazepine, and mexiletine. Anesthesiology 1991, 74: 949-51.

13 Ruth RA, Gal TJ, DiFazio CA, Moscicki JC. Brain stem auditory-evoked potentials during lidocaine infusion in humans. Arch Otolaryngol 1985; 3: 799-802.

14 Worthington DW, Brookhouser PE, Mohiuddin SM, Gorga MP. The effect of tocainide on audiological and electrophysiological responses in humans. Ear and Hearing $1985 ; 6$ : 179-83.

15 Waesterstroem SA. Auditory brain stem-evoked response after single dose injection of lidocaine and tocainide. Scand Audiol 1985; 14: 41-5.

16 Javel E, Mouney DF, McGee J, Walsh EJ. Auditory brain stem responses during systemic infusion of lidocaine. Arch Otolaryngol 1982; 108: 71-6.

17 Suzuki $M$. The effect of intravenous injection of lidocaine on the auditory system. Auris Nasus Larynx (Tokyo) 1983; 10: 25-36.

18 Woolf $C J$, Wiesenfeld-Hallin $Z$. The systemic administration of local anesthetics produces a selective depression of $\mathrm{C}$-afferent fibre evoked activity in the spinal cord. Pain 1985; 23: 361-74. 
19 Lund C, Selmar $P$, Hansen $O B$, Hjortso NC, Kehlet $H$. Effect of epidural bupivacaine on somatosensory evoked potentials after dermatomal stimulation. Anesth Analg 1987; 66: 34-8.

20 Dohi S, Kitahata LM, Toyooka H, Ohtani M, Namiki A, $T a u b A$. An analgesic action of intravenously administered lidocaine on dorsal horn neurons responding to noxious thermal stimulation. Anesthesiology 1979; 51 : 123-6.

21 deJong $R H$, Robles $R$, Corbin $R W$. Central actions of lidocaine-synaptic transmission. Anesthesiology 1969; 30: 19-23.

22 Seo N, Oshima E, Stevens J, Mori K. The tetraphasic action of lidocaine on CNS electrical activity and behavior in cats. Anesthesiology 1982; 57: 451-7.

23 Warnick JE, Kee RD, Yim GK. The effects of lidocaine on inhibition in the cerebral cortex. Anesthesiology 1971; 34: 327-32.

24 Kasaba T, Nonoue T, Yanagidani T, Maeda M, Kosaka Y. Effects of lumbar or thoracic epidural anesthesia on median nerve somatosensory evoked potential. Masui 1990; 39 : 1491-5.

25 Kasaba T, Nonoue T, Yanagidani T, Maeda M, Kosaka Y. Effects of intravenous lidocaine administration on median nerve somatosensory evoked potential. Masui 1991; 40: 713-6.

26 Gelb AW, Steinberg GK, Lam AM, Manninen PH, Peerless SJ, Rassi-Neto $A$. The effects of a prophylactic bolus of lidocaine in focal cerebral ischaemia. Can J Anaesth 1988, 35: 489-93.

27 Mackie K, Lam AM, Slee TA, Butler SH, Jacobson L. Influence of intravenous lidocaine on brain stem and somatosensory evoked potentials. Anesth Analg 1990; 70: S253.

28 Sebel PS, Flynn PJ, Ingram DA. Effect of nitrous oxide on visual, auditory and somatosensory evoked potentials. Br J Anaesth 1984; 56: 1403-7.

29 Saugbjerg $P$, Asoh $T$, Lund $C$, Kuehl $Y$, Kehlet $H$. Effects of epidural analgesia on scalp recorded somatosensory evoked potentials to posterior tibial nerve stimulation. Acta Anaestesiol Scand 1986; 30: 400-3.

30 Loughnan BA, Murdoch LI, Hetreed MA, Howard LA, Hall GM. Effects of $2 \%$ lignocaine on somatosensory evoked potentials recorded in the extradural space. $\mathrm{Br} \mathrm{J}$ Anaesth 1990; 65: 643-7. 